\title{
IX
}

\section{ENSINO DE HISTÓRIA, PATRIMÔNIO CULTURAL E HISTÓRIA LOCAL: PERSPECTIVAS PARA UM TRABALHO EDUCACIONAL NO MUNICÍPIO DE JACAREZINHO-PR*}

\author{
Vanessa Fernanda Mayrinck ${ }^{1}$ \\ Jean Carlos Moreno ${ }^{2}$
}

\section{Introdução}

O Ensino de História, o Patrimônio Cultural e a História Local são áreas do saber que estão intrinsecamente ligadas pelo elo da memória. Esses três campos possuem suas epistemologias específicas que se complementam no processo de construção do conhecimento. Durante um longo período, em contextos específicos, o ensino de História foi permeado por uma visão tradicional, que não abarcava outros instrumentos para a construção do conhecimento dos estudantes, além dos livros didáticos. Essa visão foi cristalizada por um "currículo oficial" e, infelizmente, ainda hoje, norteia algumas práticas docentes.

Repleta de vários bens patrimoniais com grande potencial para o trabalho educacional sistemático, Jacarezinho, cidade onde essa pesquisa se circunscreve, localiza-se na região que se convencionou chamar de Norte Pioneiro do Paraná. A principal narrativa que rege o município é a de que os pioneiros adentraram o território, composto por um vazio demográfico, e que trouxeram o progresso para a região. Essa narrativa possui inúmeras fissuras, prin-

\footnotetext{
"DOI - 10.29388/978-65-86678-78-9-0-f.171-184

${ }^{1}$ Aluna do programa de Pós-graduação em Educação (PPEd) da Universidade Estadual do Norte do Paraná. vanessa_mayrinck@hotmail.com

2 Pós-Doutor em História, Cultura e Identidades (UEPG). Professor do programa de Pósgraduação em Educação (PPEd) da Universidade Estadual do Norte do Paraná. jeanmoreno.uenp.edu.br
} 
cipalmente, por homogeneizar uma região que nunca foi homogênea. Podemos notar. Podemos notar a presença da ausência nessa narrativa, principalmente, quando nos perguntamos sobre os outros sujeitos que foram fundamentais para a construção da cidade, mas que não aparecem na história do município, como os trabalhadores, os negros, os índios, as mulheres...

Nesse sentido, o presente artigo, fruto da pesquisa História, Memória e Patrimônio: Uma articulação entre o Ensino de História e a Educação Patrimonial, aprovado pelo PPEd no ano de 2019, tem como principal objetivo discutir perspectivas e possibilidades para o trabalho sistemático com o ensino de História pelo viés do Patrimônio Cultural, especificamente, por meio de bens patrimoniais específicos pertencentes ao município de Jacarezinho.

\section{Ensino de História, Patrimônio Cultural e História Local: uma articula- ção possível}

O Ensino de História, o Patrimônio Cultural e a História Local são campos do saber que estão ligados pela memória. Apesar de possuírem epistemologias próprias, eles podem se tornar complementares no processo de ensinoaprendizagem.

Assim como a História e seu ensino, o Patrimônio Cultural passou por inúmeras reformulações conceituais que estão intimamente ligadas ao campo da História e das mudanças sociais, culturais, políticas e econômicas que perpassaram as sociedades.

Herança paterna; bens de família, um legado deixado às gerações posteriores. Essa é a gênese do conceito de patrimônio. Segundo Salvadori:

Um patrimônio [...] é capaz de estabelecer relações - de continuidade, ruptura, permanência ou mudança - entre as várias dimensões do tempo: o tempo passado, condensado na herança, o tempo presente, momento de seu recebimento e o tempo futuro, processo no qual vai sofrendo inúmeras mutações de sentido. Assim, um patrimônio se constitui pela valoração material e/ou simbólica, dada a um bem ou a um conjunto de bens que se deixa como herança (SALVADORI, 2008, p. 11-12). 
Essas relações de continuidade, ruptura, permanência ou mudança são dimensões fundamentais ao Patrimônio, que tem a capacidade de transcender as fronteiras do tempo e de sentido. Assim como o ensino de História, os bens patrimoniais foram utilizados como um mecanismo, em inúmeros países, com o intuito da construção e legitimação dos Estados Nacionais:

[...] o conceito de patrimônio está vinculado ao nascimento do conceito de Estado- Nação, aliado às idéias de soberania política, unidade territorial e legal, com a nação passando a indicar o conjunto de indivíduos nas cidos em um mesmo lugar (CHAUÍ 2000 apud MAGALHÃES, 2009, p. 34).

Um dos primeiros países a utilizar o patrimônio no sentido apontado por Chauí e Magalhães foi a França. No contexto pós Revolução Francesa, era preciso romper com um determinado tipo de passado e se construir uma nova nação, pautada em uma nova memória. Nesse sentido, símbolos foram escolhidos e passaram a ter dimensões nacionais, auxiliando na construção da ideia de um passado comum. Sendo assim, esses símbolos deveriam ajudar a construir uma nação pautada na homogeneização, com um passado comum e heroico, que deveria continuar sendo governada por aqueles que "lutaram arduamente por ela".

Essa perspectiva, que liga o patrimônio a um aspecto material, vinculado a um passado grandioso de uma nação, prevaleceu durante muito tempo na história. E é exatamente essa perspectiva que adentra o mundo brasileiro a partir do século XIX. De acordo com Salvadori, "como a história construída como identidade da nação, os bens entendidos como patrimônio deveriam ser objetos de culto, pois remeteriam à origem e à ancestralidade" (SALVADORI, 2008, p.16).

Bens patrimoniais que diziam respeito a uma elite branca e religiosa. Essa era a origem e a ancestralidade brasileira. Os primeiros bens tombados, já no século XX em nosso país, referiam-se, na maioria das vezes, à memória dessa elite. Bens de pedra e cal"; eram assim chamados, pois os únicos bens passíveis de tombamento eram aqueles que possuíam materialidade. 
A instituição legal para o tombamento de um bem patrimonial foi criada no Brasil na década de 30. O SPHAN (Serviço do Patrimônio Histórico e Artístico Nacional), atualmente IPHAN, tinha o intuito de eleger e preservar os bens patrimoniais materiais do país, bens estes, como citado anteriormente, que diziam respeito, na maioria das vezes a uma elite política, religiosa e econômica. Essa instituição ainda tinha um intuito maior: a construção de uma identidade nacional homogênea. De acordo com Fenelon, "esta perspectiva, que foca a unidade e a identidade nacional, foi fator de marginalização das contradições reais e tira da memória o significado da luta social por ela, e assim, pelo patrimônio" (FENELON, 1992, p.29-30).

O pesquisador Ricardo Oriá, também comenta esta visão restritiva sobre os bens patrimoniais, que reinou até a segunda metade do século XX no Brasil:

[...] preservam-se as igrejas barrocas, os fortes militares, as casas-grandes e os sobrados coloniais. Esqueceram-se, no entanto, das senzalas, dos quilombos, as vilas operárias e cortiços (ORIÁ, 1997, p. 131).

Essa perspectiva acima referenciada, entra em xeque com o processo de redemocratização do Brasil. Nessa conjuntura, a historiografia passou por inúmeras revisões no intuito de romper com um passado europeu e homogeneizador. Os conflitos passaram a ser enfatizados e os grupos sociais antes alijados da história passaram a reivindicar o seu lugar nela.

Foi nesse período que a ótica sobre o patrimônio iniciou seu processo de transformação. Essa reformulação, pautada por uma ampliação e pluralidade do conceito foi legitimada na Constituição de 1988, em seu artigo 216, seção II - DA CULTURA, onde se estabeleceu o conceito de Patrimônio Cultural:

Art. 216 Constituem Patrimônio cultural brasileiro os bens de natureza material e imaterial, tomado individualmente ou em conjunto, portadores de referência à identidade, à ação, à memória dos diferentes grupos formadores da sociedade brasileira, nos quais se incluem:

I- formas de expressão;

II- Os modos de criar, fazer e viver; 
III- As criações científicas, artísticas e tecnológicas;

IV- As obras, objetos documentos, edificações e demais espaços destinados às manifestações artístico-culturais;

V- Os conjuntos urbanos e sítios de valor histórico, paisagístico, artístico, arqueológico, paleontológico, ecológico e científico (BRASIL, 1988).

Comentando a ampliação da visão de patrimônio, legitimada agora por bens materiais e imateriais, Gilberto Gil, ministro da Cultura de 2003 à 2008, aponta que:

[...] pensar em patrimônio agora é pensar com transcendência, além das paredes, além dos quintais, além das fronteiras. É incluir as gentes. Os costumes, os sabores, os saberes. Não mais somente as edificações históricas, os sítios de pedra e cal. Patrimônio também é o suor, o sonho, o som, a dança, o jeito, a ginga, a energia vital, e todas as formas de espiritualidade de nossa gente. O intangível, o imaterial (GIL, 2008 apud ALMEIDA, 2009, p. 5).

Nesse sentido, se o patrimônio pôde ser utilizado para legitimar uma ideia de nação e construção de identidades homogêneas, o mesmo também pode ser um mecanismo auxiliador na construção de identidades plurais, pautadas na empatia e respeito, com vistas à conscientização e contra todo tipo de discriminação e opressão. Mas como realizar essa tarefa? Pensar em um trabaIho conjunto, que articule o Ensino de História, História Local e a Educação Patrimonial pode ser um caminho.

O trabalho com a História local coloca a cidade, seus símbolos e suas narrativas como o centro do processo de ensino e aprendizagem. Esse exercício torna-se possível uma vez que:

A cidade é o espaço onde se registra uma ampla troca de interesses, conhecimentos e práticas socioculturais. Ela é um produto histórico definido pelas atitudes e formas de vida próprias de uma localidade oriunda da distribuição peculiar de indivíduos em um espaço definido (MEDEIROS, 2006, p. 29).

Nesse sentido: 
O ensino de História local torna possível a utilização da própria cidade como recurso didático, uma vez que "a cidade está lá fora", apenas à espera de uma leitura, "com suas ruas, praças, avenidas, monumentos, a cidade é um caleidoscópio de imagens, cores e sons" um espaço aguardando pela (re)descoberta (POSSAMAI, 2011, p. 297).

Nesse caleidoscópio de imagens, encontram-se os bens patrimoniais que dizem respeito a um passado de determinado grupo social muitas vezes suprimido por uma narrativa pautada pela história oficial. Conhecer e decodificar esses bens a partir de uma visão crítica, fazendo afluir os conflitos e as tensões intrínsecas ao patrimônio, pode contribuir para um processo de construção do conhecimento histórico mais rico, norteado pela diversidade. A Educação Patrimonial é uma estratégia importante para efetivar esse processo.

Entendida em um primeiro momento como um "instrumento de alfabetização cultural", a Educação Patrimonial possibilita aos sujeitos uma leitura de mundo, auxiliando-os a compreender a sociedade em que vivem e a trajetória histórico-temporal na qual estão inseridos (cf. HORTA, 1999).

FLORÊNCIO (2014), apresenta um conceito plural de Educação Patrimonial, relacionando-a à educação formal/não formal e também apontando a relevância do constante diálogo com a sociedade:

[...] a Educação Patrimonial constitui-se de todos os processos educativos formais e não formais que têm como foco o Patrimônio Cultural, apropriado socialmente como recurso para a compreensão sócio-histórica das referências culturais em todas as suas manifestações, a fim de colaborar para seu reconhecimento, sua valorização e preservação. [...] Os processos educativos devem primar pela construção coletiva e democrática do conhecimento, por meio do diálogo permanente entre os agentes culturais e sociais e pela participação efetiva das comunidades detentoras e produtoras das referências culturais, onde convivem diversas noções de Patrimônio Cultural. (FLORÊNCIO et al., 2014, p. 19).

Partilhando da mesma perspectiva acima citada, Salvadori explicita que a Educação patrimonial se trata de: 
[...] propiciar informações que permitam às pessoas em geral e, particularmente no caso aqui em questão, aos alunos, perceberem a importância do passado na formação de sua identidade individual e coletiva e na construção da realidade em que estão inseridos (SALVADORI, 2008, p. 36).

A Educação Patrimonial, articulada com o ensino de História e com a História Local, deve estar ancorada em uma prática democrática, onde as narrativas que permeiam a cidade sejam trabalhadas a partir de um viés crítico; onde os sujeitos marginalizados da história da cidade sejam recolocados no seu papel como construtores da história; onde os silêncios sejam contextualizados, transformando assim, ausências em presença.

Chagas (2006, p.-01), afirma que "o patrimônio deve ser capaz de articular tensões entre o universal e o singular". Dentro da mesma ideia, MagaIhães, Zanon e Branco (2009, p. 60) afirmam que nesse sentido é importante "retomar os espaços arquitetônicos sociais e de memórias, [...] desde que se façam relações com outros elementos e que se chame atenção para as tensões das vivências e das seleções".

Similarmente às ideias apresentadas acima, Soares aponta que:

As tensões e seleções, assim como o consenso, são elementos inerentes ao patrimônio, que não podem ser ignorados por aqueles que trabalham com educação patrimonial, pois preservação e representação estão vinculados a interesses de grupos, sendo assim necessário disputar o patrimônio, o que pressupõe um duplo caminho (SOARES, 2003, p. 24)

Quando falamos sobre patrimônio, estamos também falando sobre memória(s). E quando falamos de memória(s), não podemos nos esquecer de duas palavras que a(s) permeiam: o poder e o esquecimento. Quem detém o poder, detém a memória, ou ao menos, a manipulação dela, legitimando o que deve ser lembrado e consequentemente, o que deve ser esquecido. Os bens patrimoniais são frutos desse processo e dessa "guerra fria" entre memória e esquecimento. 
Através da articulação entre o Ensino de História, História Local e da Educação Patrimonial é possível fazer com que esse conjunto de inquietações aflua. Trabalhar com o patrimônio é desconstrução, e desconstrução se faz, muitas vezes, através da análise das contradições e conflitos. Nesse sentido, esses processos devem ser enfatizados de maneira didática para os alunos e para a comunidade local. Assim, os mesmos compreenderão que os patrimônios e os processos que os legitimaram não são frutos do mero acaso, mas sim, resultados de disputas e lutas internas entre uma elite e grupos sociais marginalizados presentes na memória da cidade.

Educar pelo patrimônio é permitir "um exercício de (re)significação cultural e da construção de outros olhares sobre o patrimônio de uma determinada comunidade" (SCHIAVON; SANTOS, 2013, p. 86). Educar para a História local é "tentar buscar no recorte micro os sinais e as relações de totalidade social, rastreando-se por outro lado, os indícios das particularidades - os homens e as mulheres de 'carne e osso' (BITTENCOURT, 2004, p. 2003). Educar a partir da intersecção desses dois campos do saber é educar também para a compreensão da memória ou das memórias que permearam ou que ainda permeiam as inúmeras narrativas do município.

\section{O ensino de História sob o viés do patrimônio cultural em Jacarezinho - PR: possibilidades}

Jacarezinho, município no qual esta pesquisa se situa e se delineia, é vista por muitos como uma "cidade bucólica do interior". Emancipada no ano de 1900, ela só foi receber essa denominação em 1903. Município formado em um primeiro momento por mineiros e paulistas que buscavam novas terras para a criação de suínos e gado, logo se transformou em "cidade modelo do norte do Paraná", graças a sua força econômica que se expandia pelo conjunto da "terra rocha" mais a cultura do café, que crescia e passava por um momento de valorização em todo o país.

A partir de um exame e análise mais apurados, essa narrativa, que ainda hoje permanece no imaginário social entra em xeque. Sob um olhar mais 
delineado, percebe-se inúmeras memórias suprimidas através de uma narrativa oficial. Nessas memórias, que heroicizam o pioneiro, "responsável por trazer o progresso para a região", os negros, os índios, as mulheres e os trabalhadores não existem.

Estes sujeitos e estas memórias apagadas, esquecidas, não são trabaIhadas no ensino de História no Município, porém, parte delas foram cristaliza das nos bens patrimoniais da cidade. Por este fato, acredita-se que há inúmeras possibilidades para um trabalho crítico, plural, capaz de relacionar-se ao cotidiano dos estudantes, trazendo empatia, e, principalmente, desconstruindo ideias pré-concebidas sobre a(s) narrativa(s) que a cidade possui. Nesse sentido, os bens patrimoniais que a cidade possui, construídos, legitimados e perpetuados na memória do município, podem ser instrumentos fundamentais nesse processo.

Assim, essa pesquisa selecionou a capela São Benedito e a Catedral Imaculada Conceição, ambas localizadas em Jacarezinho, para serem os eixos norteadores da articulação entre Ensino de História, História Local e Patrimônio Cultural. Cabe salientar que nesse trabalho, transcender as fronteiras religiosas intrínsecas a esses bens será fundamental. Nesse sentido, as questões políticas, sociais e culturais serão os temas centrais do trabalho.

Como afirmado acima, os bens patrimoniais nos quais a presente pesquisa irá se delinear são a Capela São Benedito e a Catedral Imaculada Conceição. A construção da Capela São Benedito insere-se em um contexto específico: o fim do século XIX e início do século XX. Jacarezinho ainda não havia ga nhado força econômica, nem havia se transformado em Diocese. A abolição já havia sido decretada há anos, porém, a marginalização dos negros e o racismo ainda se faziam presentes na sociedade. Segundo fontes memorialísticas, na cidade residiam escravos, que vieram com os primeiros moradores do município e que, segundo essas mesmas fontes, não sabiam que haviam sido libertos: ${ }^{3}$

\footnotetext{
${ }^{3}$ Podemos questionar essa afirmação. Confrontando-a com ALBUQUERQUE; FRAGA FILHO (2006) e FRAGA FILHO (2006), o que podemos afirmar é que existiam aqueles que já estavam cientes de sua condição de liberdade e que, mesmo assim, optavam por um rearranjo dentro da situação anterior, uma vez que, a vida longe da fazenda poderia se tornar ainda mais difícil para eles e para sua família. A lei Áurea acabou legitimando a liberdade de pessoas escravizadas apenas no papel. Na prática, a marginalização dessa população ainda se fazia presente na sociedade.
} 
Aos domingos e dias Santos, os senhores iam a Igreja de São Sebastião, e não era permitido que seus escravos, que oficialmente já eram libertos mas não sabiam, pois a lei de 13 de maio de 1888 não era conhecida pelos escravos, e os senhores procuravam sempre abusar dos negros escra$\operatorname{vos}[\ldots]$ (AIMONE, s/d, p. 30, grifo do autor).

Essas pessoas que eram escravizadas, segundo Aimone, ficavam concentradas onde hoje se localiza a Rua Costa Júnior. Lá elas dançavam suas congadas e vendiam seus quitutes com o intuito de arrecadar dinheiro suficiente para construir um templo onde seu sagrado pudesse ser professado, uma vez que, os negros não podiam frequentar a catedral da cidade, pois o único padre residente no município, "não professava só a fé", mas também sentimentos e atitudes racistas:

Joaquim Inácio de Melo e Souza, único padre que veio com a caravana dos Alcântaras, somente pregava para os brancos, pois os negros escravos não tinham o direito de estarem junto com os seus senhores e seus parentes [...] (AIMONE, s/d, p. 30, grifo do autor).

Sendo assim, de acordo com o mesmo autor, um senhor conhecido como Capitão Gasparino, dono do terreno ao qual os negros se concentravam, resolveu doá-lo como obra de "caridade", para que os mesmos construíssem uma igreja. Após esse fato, eles começaram a se organizar, "isso foi em 1895, quando teve início o alicerce da nova igreja, com tijolos fabricados pelos mesmos operários, em caieiras provisórias [...] pois não existia ainda fornos de olarias" (AIMONE, s/d, p. 30, grifo do autor).

Ainda segundo o autor, a capela terminou de ser construída no ano de 1903 e, nesse mesmo ano, os negros solicitaram ao Padre Melo, a presença de outro padre, para "atender todas as solenidades que se faziam necessárias".

Assim, desde o início do século XX, a Igreja São Benedito se faz presente, de uma forma discreta na cidade de Jacarezinho. Parafraseando Aimone, até hoje, a obra "feita pelos escravos" ainda perdura.

Após explicitarmos um pouco da história da construção dessa capela, podemos então, tomar ciência da sua relevância histórica. Podemos também 
entender o porquê de sua escolha para servir de eixo norteador para o trabaIho com os estudantes.

O outro bem selecionado situa-se na Catedral Imaculada Conceição. São as pinturas de Eugênio Sigaud, famoso pintor brasileiro que veio para a cidade realizar a obra a convite de seu irmão, na época, bispo da cidade. Eugênio era conhecido como o pintor dos operários e expressou seus valores e posicionamentos políticos em cada mural que pintou. Tensões e conflitos permearam a produção dos murais. Sigaud era ateu e também comunista e esses posicionamentos e valores podem ser encontrados nos murais que pintou na Catedral de Jacarezinho.

A partir do trabalho crítico com esses bens, os alunos poderão entrar em contato com um lado da história da cidade que não conheciam, lado este, permeado por tensões e conflitos que não fazem parte da história oficial. Poderão compreender também, que a tríade Patrimônio, memória e esquecimento são entrecruzados pela poder. Por fim, terão a possibilidade de conhecer a história dos inúmeros sujeitos que foram fundamentais para o desenvolvimento de seu município, mas que foram apagados intencionalmente das narrativas oficiais da cidade.

\section{Conclusões}

Trabalhar com o ensino de História, o Patrimônio Cultural e com a História Local envolve um processo de desconstrução. A partir da história da construção e perpetuação dos bens elencados, permeada por conflitos e tensões, os alunos poderão compreender que o Patrimônio não é uma via de mão única e que nunca existirá uma história universal e homogênea sobre um bem patrimonial, mas sim, lutas e disputas que são mediadas por relações de poder que permeiam a sociedade.

Sabemos que as cidades "educam olhares", que conseguem exprimir através de mecanismos específicos o implícito da sociedade. Elas são claras e ao mesmo tempo misteriosas. A cidade de Jacarezinho não possui traços diferentes dos citados acima. 
Com inúmeras memórias suprimidas por uma narrativa oficial, alguns sujeitos da história foram produzidos como não existentes. Parte dessas memórias foram cristalizadas nos bens patrimoniais da cidade. Nesse sentido, a partir da intersecção entre o ensino de História, História Local e Patrimônio Cultural, é possível auxiliar os estudantes a compreender diversos pontos de vista sobre a história, ajudá-los no desenvolvimento de sua consciência história, quebrar paradigmas e conceituações rasas pode contribuindo assim para a preservação e valorização de bens patrimoniais antes marginalizados, transformando os jovens estudantes em cidadãos conscientes e críticos. Além disso, através dessa intersecção, é possível "fazer falar a multidão imensa dos figurantes mudos que enchem o panorama da história [...]" (BITTENCOURT, 2005, p.201) e recolocá-los como sujeitos históricos, enfatizando seu papel fundamental na construção e desenvolvimento da História do município.

\section{Referências}

AIMONE, Thomaz. Meu Ginásio Rui Barbosa. Jacarezinho-PR: s/e: 1988

ALBUQUERQUE, Wlamyra Ribeiro de; FRAGA FILHO, Walter. Uma história do negro no Brasil. Salvador: Centro de Estudos Afro-Orientais; Brasília: Fundação Cultural Palmares, 2006.

ALMEIDA, Luiz Fernando de. Educação e Patrimônio Cultural: Por uma nova atitude. In: Por dentro da História. Contagem, MG: Revista de Educação Patrimonial, num.1, 2009.

BITTENCOURT, Circe Maria Fernandes. Ensino de História: fundamentos e métodos. São Paulo: Cortez, 2004.

BITTENCOURT, Circe Maria Fernandes. Identidade Nacional e ensino de história do Brasil. In: KARNAL, Leandro (org.). História na sala de aula: conceitos, práticas e propostas. 4 ed. São Paulo: Contexto, 2005. 
CHAGAS, Mário. Educação, Museu e Patrimônio: Tensão, Devoração e Adjetivação. Patrimônio: Revista Eletrônica do IPHAN. Dossiê: Educação Patrimonial. No. 03, jan/fev 2006.

CHAUÍ, Marilena. Política Cultural, Cultura Política e Patrimônio Histórico. In: 0 Direito à Memória: Patrimônio Histórico e Cidadania. São Paulo: Secretaria Municipal de Cultura do Município de São Paulo / Departamento do Patrimônio Histórico - DPH, 1992.

FENELON, Déa R. "Políticas Culturais e Patrimônio Histórico". In: Cultura e Memória: Perspectivas da Administração Pública Brasileira Hoje. Brasília: Cadernos ENAP, vol. 1, n. 2, 1992.

FRAGA FILHO, Walter. Encruzilhadas da liberdade. História de escravos e libertos na Bahia (1870-1910). Campinas: Editora da Unicamp, 2006.

FLORÊNCIO, Sônia R. R.; CLEROT, Pedro; BEZERRA, Juliana; RAMASSOTE, Rodrigo. Educação Patrimonial: histórico, conceitos e processo. Brasília, DF: Iphan/DAF/Cogedip/Ceduc, 2014.

HORTA, Maria de Lourdes Parreiras. GRUNBERG, Evelina; MONTEIRO, Adriane Queiroz. Guia Básico de Educação Patrimonial. Brasília: Instituto do Patrimônio Histórico e Artístico Nacional / Museu Imperial, 1999.

MEDEIROS, Ricardo. Um olhar sobre o patrimônio histórico-arquitetônico de Assú/RN: análise com base na percepção dos usuários e no ponto de vista técnico. Natal, 2006. 164p. Dissertação (Mestrado em Arquitetura e Urbamnismo), Programa de Pós-Graduação em Arquitetura e Urbanismo. Natal: UFRN, 2006.

ORIÁ, Ricardo. Educação patrimonial: conhecer para preservar. Portal Educacional, 2006. 
POSSAMAI, Zita Rosane. Cidade: escritas da memória, leituras da história (org). Leituras da cidade. Porto Alegre: Evangraf, 2010.

SALVADOR, Maria Ângela Borges. História, Ensino e Patrimônio. Araraquara, SP: Junqueira \& Marin, 2008.

SANTOS, Anderson Cunha. Patrimônio cultural e história local: a educação patrimonial como estratégia de reconhecimento e fortalecimento do sentimento de pertença à cidade de contagem. 116f., 2017. Dissertação - (Mestrado Profissional em Educação e Docência ) - Universidade Federal de Minas Gerais, Faculdade de Educação, 2017.

SOARES, André Luis Ramos (Org.). Educação Patrimonial: Relatos e Experiências. Santa Maria-RS: UFSM, 2003.

SCHIAVON, Carmem G. Burgert; SANTOS, Tiago Fonseca dos. Patrimônio, ambiente e ensino em Rio Grande: elementos para interpretação e valorização de bens culturais. v. 2. Rio Grande: Editora da FURG, 2013.

ZANON, Elisa Roberta; MAGALHÃES, Leandro Henrique; BRANCO, Patrícia Martins Castelo. Educação Patrimonial: da teoria à prática. Londrina, PR: UniFil, 2009. 